\title{
Research Article \\ Effects of Particle Size and Cement Replacement of LCD Glass Powder in Concrete
}

\author{
Seong Kyum Kim, ${ }^{1}$ Su Tae Kang, ${ }^{2}$ Jin Kwang Kim, ${ }^{3}$ and Il Young Jang ${ }^{4}$ \\ ${ }^{1}$ Department of Civil and Environmental Engineering, Hanyang University, 55 Hanyangdaehak-ro, Sangnok-gu, \\ Ansan, Gyeonggi-do 15588, Republic of Korea \\ ${ }^{2}$ Department of Civil Engineering, Daegu University, 201 Daegudae-ro, Jillyang, Gyeongsan, Gyeongbuk-do 38453, Republic of Korea \\ ${ }^{3}$ Safety and Disaster Management Division, Korea Expressway Corporation, 77 Hyeoksin 8-ro, Gimcheon, \\ Gyeongbuk-do 39660, Republic of Korea \\ ${ }^{4}$ Department of Civil Engineering, Kumoh National Institute of Technology, 61 Daehak-ro, Gumi, \\ Gyeongbuk-do 39177, Republic of Korea \\ Correspondence should be addressed to Il Young Jang; jbond@kumoh.ac.kr
}

Received 7 October 2016; Accepted 28 November 2016; Published 30 January 2017

Academic Editor: Kazunori Fujikake

Copyright (C) 2017 Seong Kyum Kim et al. This is an open access article distributed under the Creative Commons Attribution License, which permits unrestricted use, distribution, and reproduction in any medium, provided the original work is properly cited.

The high quality liquid crystal display (LCD) processing waste glass (LPWG) generated from the manufacturing process of Korea's LCD industries, having the world's highest technological level and production, was finely ground into particles smaller than cement particles (higher fineness than OPC) to verify their applicability and performance as a replacement for cement. For a concrete mix having a W/B ratio of 0.44 , cement was replaced with LPWG glass powder (LGP) at ratios of 5, 10, 15, and 20\% (LGP12) and 5 and $10 \%$ (LGP5) according to the particle size to prepare test cylinder specimens, which were tested with respect to air contents, slump in fresh concrete, and compressive strength and splitting tensile strength of hardened concrete. The microstructure of the concrete specimens was analyzed through Scanning Electron Microscopy (SEM), Energy Dispersive X-ray (EDX), and a Mercury Intrusion Porosimetry (MIP). Replacement of cement with LGP for cement could effectively decrease the quantity of cement used due to the excellent performance of LGP. It may positively contribute to the sustainable development of the cement industry as well as waste recycling and environment conservation on a national scale.

\section{Introduction}

The 21st century's concrete and cement technology requires various functions, durability, and quality stability to attain sustainability, environment-friendliness, high performance, high strength, and economic feasibility. In harmony with these requirements, many researchers have made efforts to reduce the utilization of cement and to maximize the performance [1-4]. In particular, liquid crystal display (LCD) waste glass has been produced in a large amount due to the development of the display industry. The international display market share was $39.2 \%$ in Korea, $27.4 \%$ in Taiwan, $15.5 \%$ in China, and $17.9 \%$ in other countries in 2015. Korea's investment in the LCD industry is as high as 27 billion USD per year, and the production in Korea is 480,000 panels per month (the 8th generation, 50 inches), which is the highest in the world. On the basis of the production of mobile devices, such as smartphones and tablet PCs, and the future demand, LCD production is predicted to continuously increase. Accordingly, the amount of waste LCD has increased since the early 2000s to reach 2 million panels or more in 2015, and the weight of waste LCD generated each year is about 460,000 tons [5]. As most waste LCD is incinerated or buried, it wastes resources and causes various types of environment pollution on a national scale [6].

LCD waste glass is classified into three categories: (1) LCD cullet, (2) LCD waste glass, (LPWG), and (3) end of life (EOL) LCD waste glass. LPWG, used in this study, is waste glass generated from LCD manufacturers due to defects in processing and cutting or bonding in the LCD 
TABLE 1: Physical properties of cement.

\begin{tabular}{lccccccc}
\hline \multirow{2}{*}{ Specific gravity } & \multirow{2}{*}{ Blaine $\left(\mathrm{cm}^{2} / \mathrm{g}\right)$} & \multirow{2}{*}{ Stability $(\%)$} & \multicolumn{2}{c}{ Setting time } & \multicolumn{3}{c}{ Compressive strength (MPa) } \\
& & & Initial $(\mathrm{min})$ & Final $(\mathrm{min})$ & 3 days & 7 days & 28 days \\
\hline 3.15 & 3,450 & 0.04 & 205 & 295 & 29.5 & 43.8 & 58.9 \\
\hline
\end{tabular}

TABLE 2: Physical properties of sand and aggregate.

\begin{tabular}{lccccc}
\hline & Fineness modulus (FM) & Water absorption (\%) & Weight of unit volume $\left(\mathrm{kg} / \mathrm{m}^{3}\right)$ & Specific Gravity & Others \\
\hline Fine aggregate & 2.92 & 2.40 & 1,597 & 2.60 & Pass $2.2 \%(\# 200$ sieve $)$ \\
Coarse aggregate & 7.27 & 0.6 & 1,648 & 2.65 & $20 \mathrm{~mm}\left(D_{\text {Max }}\right)$ \\
\hline
\end{tabular}

TABLE 3: Mix proportions of concrete with WLGP.

\begin{tabular}{|c|c|c|c|c|c|c|c|c|c|}
\hline \multirow{2}{*}{$\mathrm{W} / \mathrm{C}(\%)$} & \multirow{2}{*}{ Unit water content $\left(\mathrm{kg} / \mathrm{m}^{3}\right)$} & \multirow{2}{*}{ S/a (\%) } & \multirow{2}{*}{\multicolumn{2}{|c|}{ LCD glasses powder content (\%) }} & \multicolumn{5}{|c|}{ By the mass of binder $\left(\mathrm{kg} / \mathrm{m}^{3}\right)$} \\
\hline & & & & & $\mathrm{C}$ & $\mathrm{S}$ & G & LGP & SP \\
\hline \multirow{7}{*}{44} & \multirow{7}{*}{175.03} & \multirow{7}{*}{43.7} & \multicolumn{2}{|c|}{ OPC } & 397.8 & & & 0 & 3.9 \\
\hline & & & \multirow{4}{*}{$12 \mu \mathrm{m}$} & 5 & 377.9 & & & 19.9 & 3.7 \\
\hline & & & & 10 & 358.0 & & & 39.8 & 3.5 \\
\hline & & & & 15 & 338.1 & 705.3 & 943.1 & 59.7 & 3.3 \\
\hline & & & & 20 & 318.2 & & & 79.6 & 3.1 \\
\hline & & & \multirow{2}{*}{$5 \mu \mathrm{m}$} & 5 & 377.9 & & & 19.9 & 3.7 \\
\hline & & & & 10 & 358.0 & & & 39.8 & 3.5 \\
\hline
\end{tabular}

manufacturing process. Such elements as $\mathrm{Cu}, \mathrm{Mn}, \mathrm{Mo}$, and Fe may exist at a ppm level on the glass surface due to chemical processing in the manufacturing process. LCD products including these elements may not be recycled due to product quality degradation that occurs during remelting, and thus they are incinerated or buried. About 40,000 tons of LPWG in 2015, which is unavoidable waste from the LCD manufacturing process, is generated each year, and the amount of generated LPWG is dependent on the LCD market size [7].

Studies on waste glass as a replacement material for cement have been conducted with soda-lime glass, which may cause expansion or cracking through a reaction of alkalis ( $\mathrm{Na}$ and $\mathrm{K}$ ), which are contained in considerable amounts in soda-lime glass, with silica $\left(\mathrm{SiO}_{2}\right)$ [8]. Considering the alkali-silica reaction is very important when using a material for the replacement of cement. However, the dependency of the reactivity of glass on the type, components, and physical properties of glass should also be taken into account [9]. In particular, ground glass powder, as a Pozzolanic material, has an effect of reducing alkali-aggregate reaction (AAR) and inhibiting alkali-silica reaction (ASR) in the paste $[10,11]$. The LCD used in this study may be appropriately used as a replacement material for cement because the LCD is free of alkalis (particularly $\mathrm{Na}$ ) due to the intended use of the LCD product and has constant material quality $[12,13]$. In addition, the LCD contains $\mathrm{SiO}_{2}$ as the main component, which is similar to silica fume (SF), fly ash (FA), and blast furnace slag (BS) that enable improved Pozzolanic reactivity $[14,15]$. Many researchers have recently investigated LCD because of these advantages. In particular, many reports have been published in Taiwan, which has the second highest LCD market share in the world. Most of the research conducted in
Taiwan has been focused on methods of replacement LCD as an aggregate. Studies about using LCD as a replacing material for cement have not been conducted sufficiently yet [16-20]. In this study, LPWG generated in the manufacturing process of glass for LCD was investigated experimentally to improve the properties and performance as a replacement material for cement or as a binder for concrete.

\section{Materials and Methods}

2.1. Materials. The cement complied with KS L 5201 Ordinary Portland Cement. The physical properties of the cement are shown in Table 1. And, the standard sand was used as fine aggregate. Aggregate has a $20 \mathrm{~mm}$ nominal maximum size $\left(D_{\max }\right)$ which was used as coarse aggregate. The physical properties of the aggregates are shown in Table 2. LPWG powder (LGP) was provided by Inno Co. Ltd. in Korea. The pure alkali-free glass is used only, such as $0.4 \sim 1.1 \mathrm{~mm}$ the average film thickness and the other chemical compositions are not indicated. Also, two different types of LGP, according to the average diameter and fineness, were used in this study. It was ground separately through the ball mill to distinguish the spread of two different diameter; its density is 2.79 .

2.2. Specimens and Test Variables. The concrete mixer was used to make cylindrical specimens such as Table 3. After the dry mixing was completed, admixture and water were added to the concrete mix. Two types of LGP were based on the 0.44 $\mathrm{W} / \mathrm{B}$ ratio. It was replaced every $5 \%$ by the mass of OPC up to $20 \%$ (LGP12), such as $5 \%, 10 \%, 15 \%$, and $20 \%$, for the effective and efficient performance as a replacement of cement $[4,16$, 20]. In addition, a total of seven types of the specimens were 
TABLE 4: Test method for concrete with LGP.

\begin{tabular}{lcc}
\hline Test item for concrete & $\begin{array}{c}\text { Test method } \\
\text { (KS, Korea } \\
\text { Standard) }\end{array}$ & Reference (ASTM) \\
\hline $\begin{array}{l}\text { Fresh concrete } \\
\text { Air content }\end{array}$ & KS F 2421 & ASTM C 231 \\
Slump & KS F 2402 & ASTM C 143 \\
\hline Hardened concrete & KS F 2405 & ASTM C 39 \\
$\begin{array}{l}\text { Compressive strength } \\
\text { Splitting tensile strength }\end{array}$ & KS F 2423 & ASTM C 496 \\
\hline Microstructure & - & - \\
SEM & - & - \\
EDX & - & - \\
MIP & & \\
\hline
\end{tabular}

made, including two different types of specimens that were replaced by high fineness LGP (LGP5) such as 5\% and 10\%. Water reducing admixture (superplasticizer, SP) based on Polycarboxylate (Dongnam Ltd. Co. FlowMix 3000S, specific gravity: $1.05 \pm 0.05, \mathrm{pH}: 5.0 \pm 1.5$ ) was added at $1 \%$ for a high strength and improving the workability of concrete. The specimens were followed by KS F 2403 specification which made $100 \times 200 \mathrm{~mm}$ cylindrical concrete specimens and it cured for 24 hours in the mold. After that, specimens were cured in moist curing chamber $\left(21 \pm 2^{\circ} \mathrm{C}, 100 \% \mathrm{RH}\right)$ for the each necessary period, such as $3,7,14$, and 28 days.

2.3. Analysis Methods. LGP concrete specimens including OPC concrete were performed following test of the fresh and hardened concrete. The tests applied in this study to investigate the properties of concrete containing LGP as cement replacement are shown in Table 4.

(1) Test for Air Content of Fresh Concrete by Pressure Method. The measuring steel vessel had a capacity of $7 \mathrm{~L}$ and a minimum diameter equal to 0.75 to 1.25 times height of cylindrical in shape. Working pressures of 7.5 to 30.0 psi (51 to $207 \mathrm{kPa}$ ) had been used satisfactorily.

(2) Test for Slump of Concrete. The following form of mold shell was used in this test: the top, $100 \mathrm{~mm}$ in diameter; the base, $200 \mathrm{~mm}$ in diameter; the height, $300 \mathrm{~mm}$; and the thickness, $1.5 \mathrm{~mm}$. After the mold is removed immediately from the concrete by raising it, we measured its collapsed height.

(3) Test for Compressive Strength of Concrete. The specimens were made by following the KS F 2403 and measured by a consistent load of added force $(0.6 \pm 0.4 \mathrm{MPa} / \mathrm{s})$ until the specimens were the failure from the compression tester. 7 types of specimens were conducted on $3,7,14$, and 28 days.

(4) Test for Splitting Tensile Strength of Concrete. The specimens were made by following the KS F 2403 and measured by a consistent load of added force $(0.06 \pm 0.04 \mathrm{MPa} / \mathrm{s})$ until the specimens were the failure from the UTM tester. 7 types of specimens were conducted on 28 days.

(5) SEM-EDX. Through the scanning electron microscope (SEM), which was able to use EDX (energy dispersive Xray), we confirmed the microstructure of LGP concrete. The cement paste was observed in the hydration process and we analysed compositions of the specific point in image. The equipment "JSM-6500F" was made by "JEOL" that supported $0.5 \mathrm{kV} \sim 20 \mathrm{kV}, 1.5 \mathrm{~nm}(15 \mathrm{kV})$. It was conducted 7 types of specimens on 3 and 28 days.

(6) MIP. In order to confirm the internal pore size and pore distribution of the concrete specimens on the 7 and 28 days, it was measured by the Mercury Intrusion Porosimetry (MIP) method after using the 24-hour drying oven. The equipment "POROSIMETER" was made by "Micromeritics" that supported 60,000 psi of maximum pressure and 0.003 $360 \mu \mathrm{m}$ range of pore size.

\section{Results and Discussion}

3.1. Characteristics of LGP. LGP as a replacement for cement was classified into two types depending on particle size. High fineness of the glass power may enable improved Pozzolanic activity, and the particle size is a critical parameter regarding the characteristics of the Pozzolanic reaction [21]. Therefore, the first type of LGP12 was prepared as particles size of $12.651 \mu \mathrm{m}$, which is similar to that of cement, and the second type LGP5 with fine particles size of $5.807 \mu \mathrm{m}$ with particle size about two times smaller than that of cement. Both types of LGP contained fine powder smaller than $1 \mu \mathrm{m}$. Figure 1 shows the particle size distribution of the two LGP types.

LGP used in the experiment was prepared by using a Ball mill to obtain an average particle size smaller than that of OPC in order to increase the applicability and performance as a replacement for cement. While the size of the smallest particles of OPC is about 3 to $5 \mu \mathrm{m}$, LGP used in test included some particles having a size smaller or slightly greater than $1 \mu \mathrm{m}$. In other words, the fine powder of LGP is smaller than OPC, although the pattern of the particle size distribution of the LGP was similar to that of OPC. The smaller particle size of LGP may help to improve the strength and durability of the cement paste in a concrete, either physically or chemically, as LGP contributes the role of filler or participates in the Pozzolanic reaction [21]. Figure 2 shows SEM images of the cement and the two types of LGP. Since the magnification of all the images is 1,000 times, the size of the particles may be compared with each other. As shown in Figure 2, the particle size of the LGP was smaller than that of OPC, and the LCP particles were smooth on the surface but rough at the edges. Table 5 indicates the chemical properties of LGP and compares the compositions with those of OPC. The basic chemical compositions of the LGP were $\mathrm{SiO}_{2}(60.1 \%)$ and $\mathrm{Al}_{2} \mathrm{O}_{3}$ (16.1\%). LGP having low alkali content and a rich $\mathrm{SiO}_{2}$ content may be hydrated with more $\mathrm{Ca}(\mathrm{OH})_{2}$ to enhance the Pozzolanic reaction. 


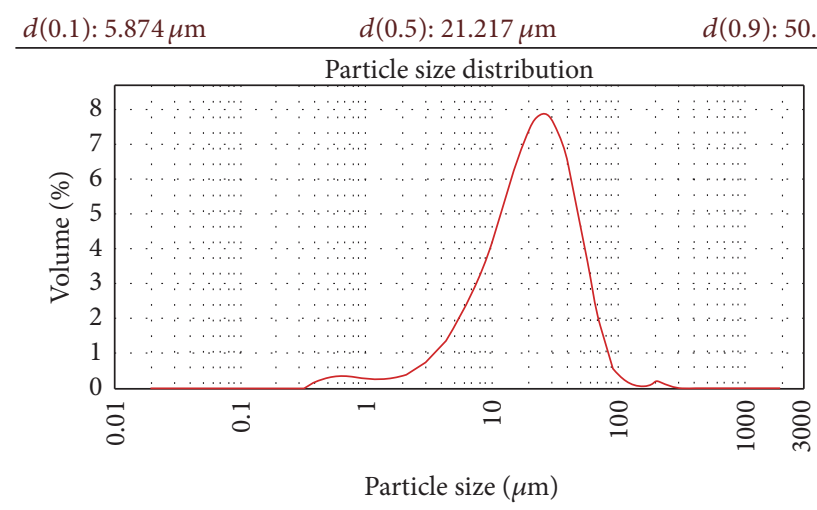

(a)

\begin{tabular}{lcc}
$d(0.1): 1.941 \mu \mathrm{m}$ & $d(0.5): 12.651 \mu \mathrm{m}$ & $d(0.9): 72.400 \mu \mathrm{m}$ \\
\hline Particle size distribution
\end{tabular}

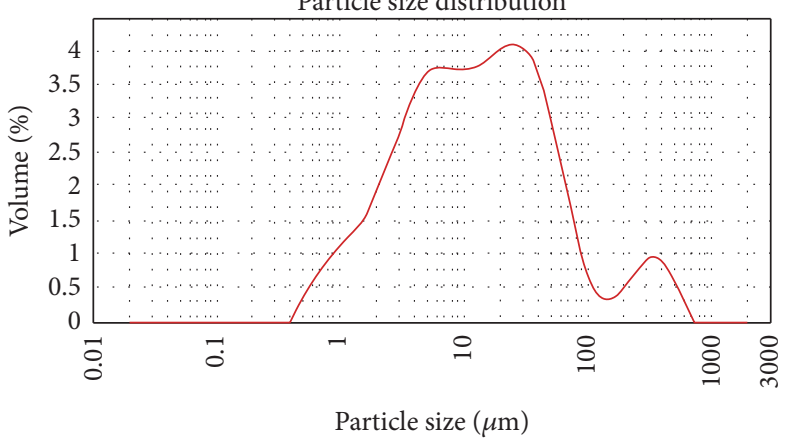

(b)

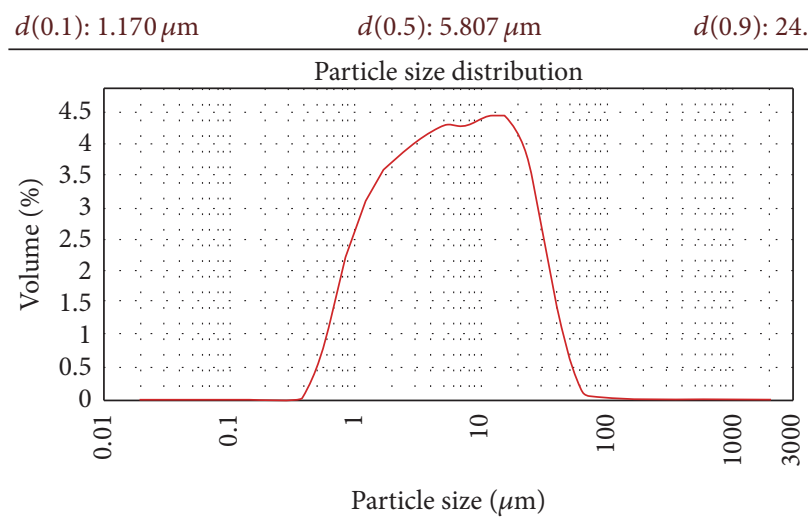

(c)

FIGURe 1: Particle size distributions of OPC (a), LGP12 (b), and LGP5 (c).

3.2. Air Content. Figure 3 shows the air content depending on LGP particle size and replacement. The overall air content was from $1.8 \%$ to $2.4 \%$, which was lower than that of OPC. Comparison of the air content between LGP of different sizes showed that the air content was higher in LGP5 than in LGP12. Comparison of the air content of LGP with different replacement ratios showed that the air content was reduction in the LGP having a replacement ratio up to $10 \%$. Soliman and Tagnit-Hamou replaced cement with fine glass powder (with a particle size less than $30 \mu \mathrm{m}$ ) in high-strength concrete (containing PC based SP admixture) at a replacement ratio from $10 \%$ to $50 \%$, by increments of $10 \%$ and reported that the air content was increased by $0 \%, 10.52 \%, 7.89 \%, 10.53 \%$, and $23.68 \%$, respectively [22]. The high specific surface area, nonabsorbability, and friction depending on particle form of LGP may reduce the workability when LGP replaces cement in concrete. Therefore, adding a proper amount of admixture (SP) may be appropriate to secure workability and durability of high fineness LGP.

3.3. Slump. The slump test with LGP12 having a replacement of $5 \%$ and $10 \%$ was higher than that of the other substitution amounts and OPC. Figure 4 shows result of slump with 


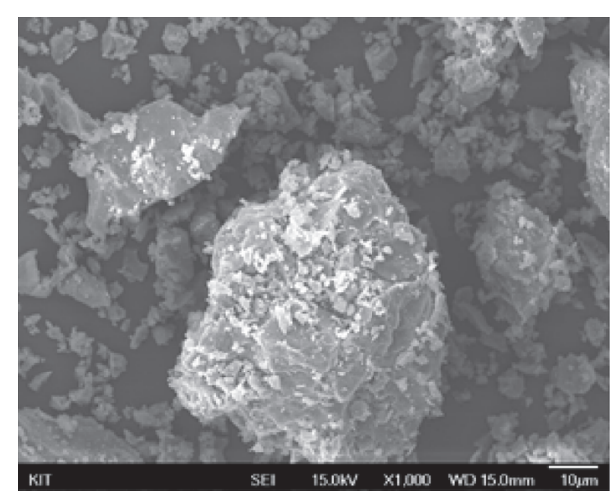

(a)

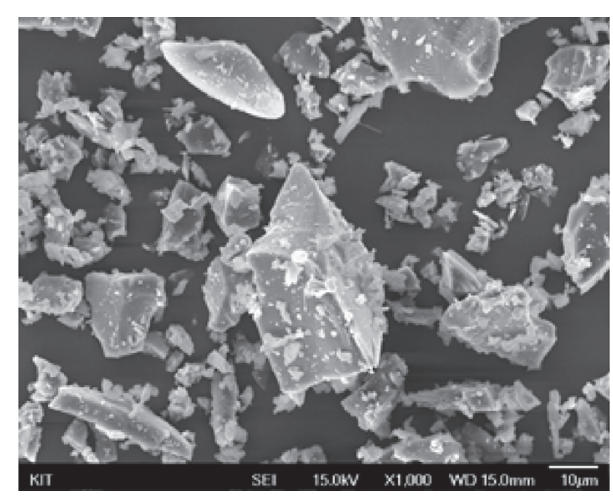

(b)

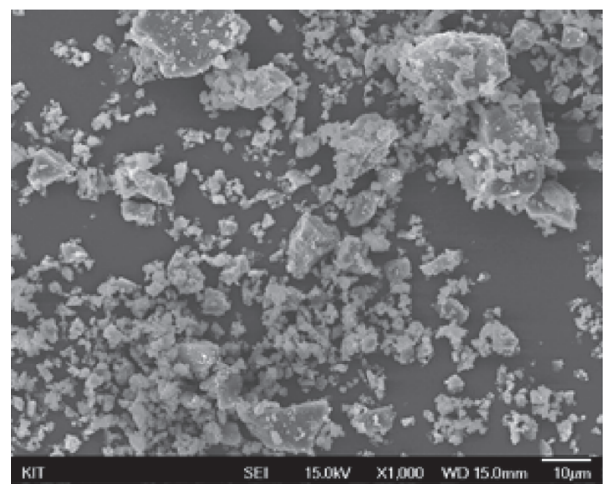

(c)

FIGURE 2: SEM images $(\times 1,000)$ of (a) cement, (b) LGP12, and (c) LGP5.

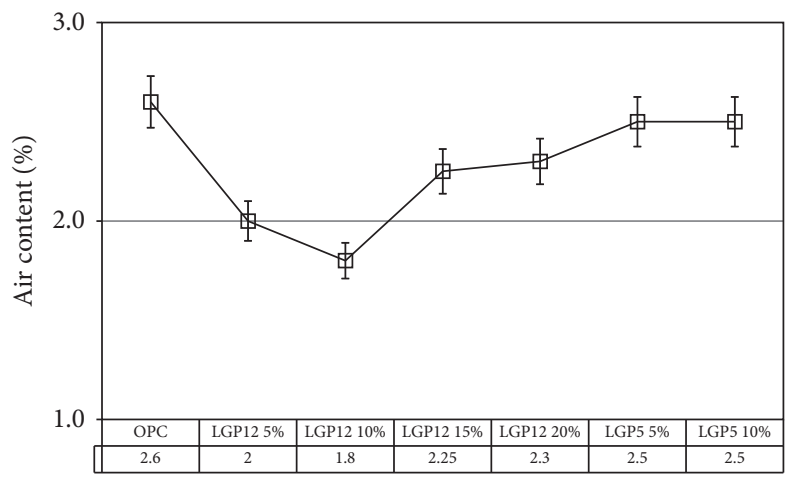

FIGURE 3: Air content of concrete with LGP amount.

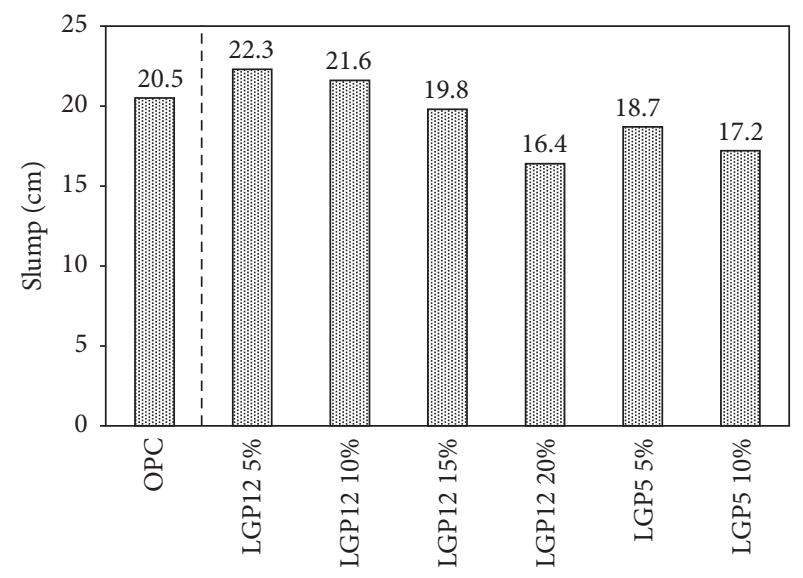

FIGURE 4: Slump of concrete with LGP amount.

different replacement and LGP particle size. The slump of LGP12 having a replacement of $10 \%$ was higher than that of OPC, although it slightly decreased when compared with a replacement ratio of $5 \%$. This result indicates improved slump caused by the lower absorptivity and smooth particle surface of LGP despite the similar particle sizes [18]. However, the slump behavior in LGP12 replacement of 15\% and $20 \%$ was significantly reduction. The slump of fresh concrete is influenced by the material roughness or shape even when the particle size is similar. As shown in the SEM images of Figure 2(b), the surface and the edges of LGP particle were angled and sharp. The effect of the surface roughness resulted in decrease of the slump at replacement of $15 \%$ or more. In the case of LGP5, the slump at a replacement of 5\% was lower than that of OPC by $16 \%$ and the trend of decreased slump at replacement ratios of $10 \%$ or higher was similar to that of LGP12. The decrease of the slump in LGP5 may be attributed to the increase of specific area and aggregation, because LGP5 was added at a higher fineness due to the fact that larger water demand generally results in a decrease in compactness [11]. 
TABLE 5: Composition of the ordinary Portland cement and LCD glass powder by XRD.

\begin{tabular}{|c|c|c|c|}
\hline & \multirow{2}{*}{ OPC } & \multicolumn{2}{|c|}{ LCD glass powder } \\
\hline & & LGP12 & LGP5 \\
\hline $\begin{array}{l}\text { Fineness }\left(\mathrm{cm}^{2} / \mathrm{g}\right) \\
\text { KS L } 5106\end{array}$ & 3,450 & 2,729 & 4,462 \\
\hline Density $\left(\mathrm{g} / \mathrm{cm}^{3}\right)$ & 3.15 & 2.79 & \\
\hline $\mathrm{SiO}_{2}(\%)$ & 21.7 & 60.1 & \\
\hline $\mathrm{Na}_{2} \mathrm{O}(\%)$ & - & 0.07 & \\
\hline $\mathrm{MgO}(\%)$ & 3.2 & 0.85 & \\
\hline $\mathrm{K}_{2} \mathrm{O}(\%)$ & - & 0.01 & \\
\hline $\mathrm{Ca}(\%)$ & 63.1 & 7.3 & \\
\hline $\mathrm{Fe}_{2} \mathrm{O}_{3}(\%)$ & 3.2 & 0.04 & \\
\hline $\mathrm{Al}_{2} \mathrm{O}_{3}(\%)$ & 5.7 & 16.1 & \\
\hline $\mathrm{TiO}_{2}(\%)$ & - & 0.02 & \\
\hline $\mathrm{ZrO}_{2}(\%)$ & - & 0.05 & \\
\hline $\mathrm{CuO}(\%)$ & - & 0.02 & \\
\hline $\mathrm{BaO}(\%)$ & - & 0.41 & \\
\hline $\mathrm{SrO}(\%)$ & - & 4.25 & \\
\hline $\mathrm{SnO}_{2}(\%)$ & - & 0.25 & \\
\hline $\mathrm{B}_{2} \mathrm{O}_{3}(\%)$ & - & 10.1 & \\
\hline $\mathrm{SO}_{3}(\%)$ & 2.2 & - & \\
\hline Ig-Loss (\%) & 0.9 & 0.43 & \\
\hline
\end{tabular}

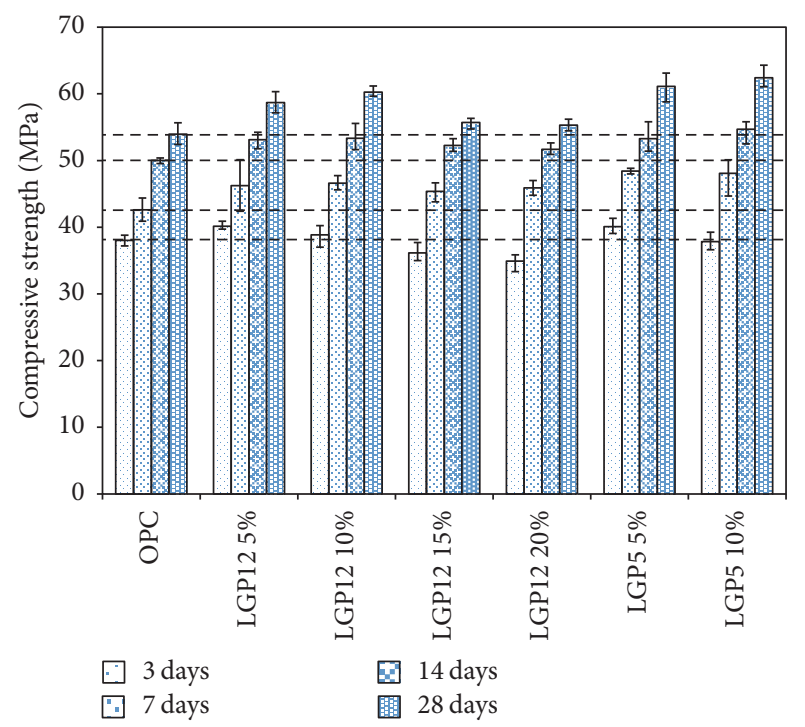

FIGURE 5: Comparison on each age strength development of LGP concrete cylinders.

3.4. Compressive Strength. Figure 5 shows the compressive strength of concrete at different curing days with the LGP depending on the replacement ratio for OPC. The overall compressive strength of LGP concrete was high, likely because of the water-reducing effect of an added polycarbonate admixture (SP) and the increase of the dispersion and plasticity. The effect of the environmental conditions of the experiment (specifically the curing temperature, where the average air temperature during the experiment was

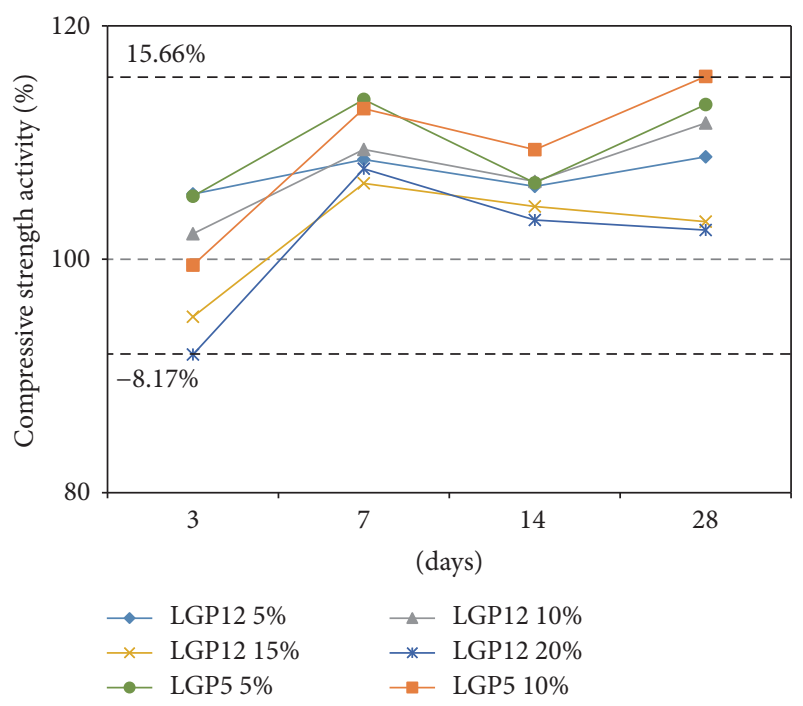

FIGURE 6: Relationship of compressive strength activity and age.

exceeding $38^{\circ} \mathrm{C}$ ) should also be taken into account. Increased curing temperature accelerates the activation of Pozzolanic materials including glass powder, and then the compressive strength indicated that the glass powder had a greater effect on the Pozzolanic material activation than fly ash [23]. The compressive strength of LGP concrete specimens was generally higher than that of OPC, except in the early age (3 days). Figure 6 shows the compressive strength activity in comparison with OPC. On 3 days, the compressive strength of LGP12 replacement of $15 \%$ and $20 \%$ was lower than OPC by $4.93 \%$ and $8.17 \%$, respectively. However, the compressive strength of all the specimens was higher than that of OPC after 7 days. The compressive strength was the highest in LGP replacement of 5\%, regardless of the particle size before 14 days. However, the compressive strength was the highest in both LGP12 and LGP5 replacement of 10\% after 14 days. In particular, the compressive strength of LGP5 was notably increased. This is because the Pozzolanic materials begin in earnest contribution to the Pozzolanic reaction 3 to 14 days after the hydration has begun. At that time, approximately $70 \%$ to $80 \%$ of Alite in OPC already proceeded to reaction [24]. Therefore, the Si and Al ions eluted from LGP may have reacted with the $\mathrm{Ca}$ ions included in the pore solution to produce C-S-H and C-A-H to make the dense and more compact. Comparison of the compressive strength with different particle sizes (LGP5 and LGP12) showed a higher compressive strength of LGP5 than LGP12 after 7 days. This result clearly showed the effect of LGP replacement on the concrete, and smaller particle size and high fineness as replacement for cement may increase not only the compressive strength but also the durability. Therefore, the Pozzolanic material activation may be enhanced by fine grounding the LGP into smaller particles [15, 25-27].

3.5. Splitting Tensile Strength. The splitting tensile strength of LGP concrete was similar to OPC (see Figure 7). The splitting tensile strength was increased as the compressive strength of LGP was increased. LGP12 5\% showed the highest 


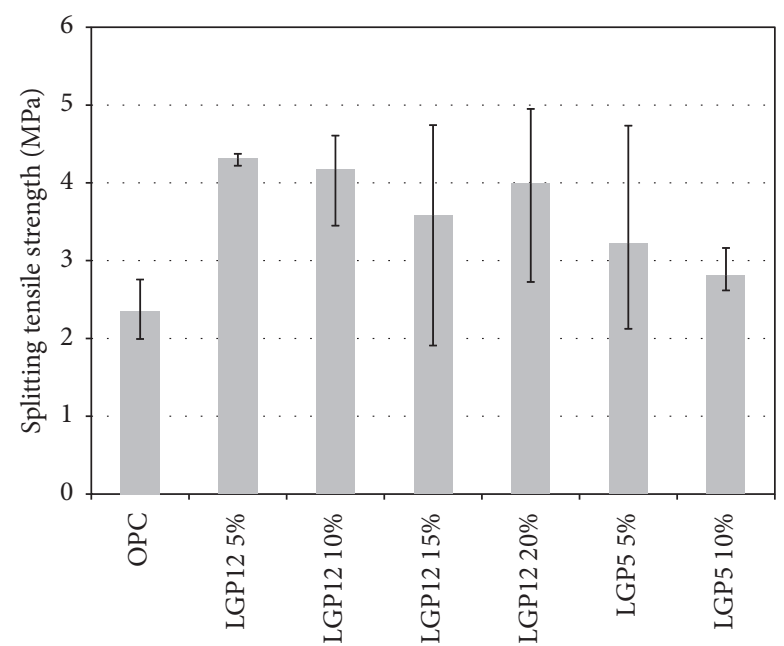

FIGURE 7: Comparison on splitting tensile strength of LGP concrete cylinders.

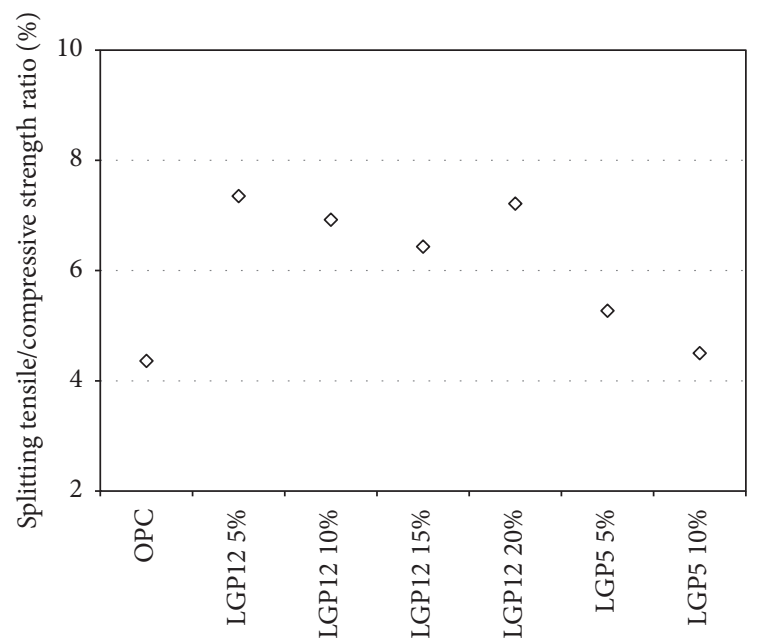

FIGURE 8: Relationship of splitting tensile by compressive strength ratio and LGP proportion.

splitting tensile strength, $4.31 \mathrm{MPa}$, which was $83 \%$ higher than that of OPC. LGP5 10\% specimen showed the lowest splitting tensile strength, $2.81 \mathrm{MPa}$, which was $19 \%$ higher than that of OPC. However, the splitting tensile strength tends to decrease with increasing proportion of LGP replaced. Figure 8 shows relationship of splitting tensile by compressive strength ratio and LGP proportion on 28 days. LGP12 5\% specimen showed the highest ratio, $7.35 \%$. The ratio of OPC was $4.36 \%$. Mcdonald reported the splitting tensile by compressive strength ratio in a range from $5.8 \%$ to $8.2 \%$ in concrete mixed with silica fume, a Pozzolanic material, at same ages [28]. The splitting tensile by compressive strength ratio of hardened concrete is dependent on the properties of added materials. The results showed that LGP had a positive effect on the enhancement of the splitting tensile.

3.6. Interfacial Microstructure SEM of Concrete. The interfacial microstructure of the specimens was analyzed at different

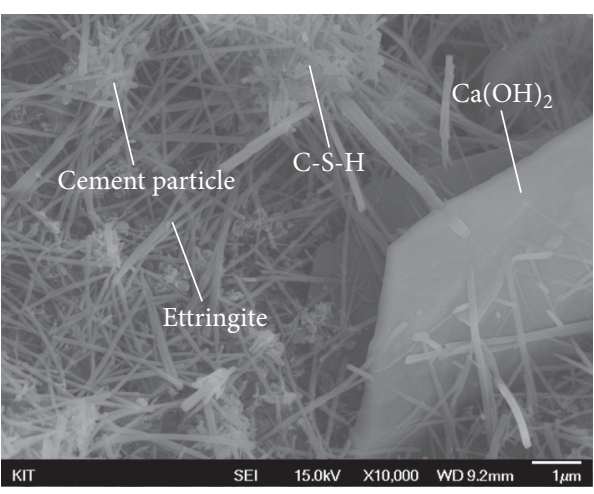

Figure 9: SEM image of OPC (3 days).

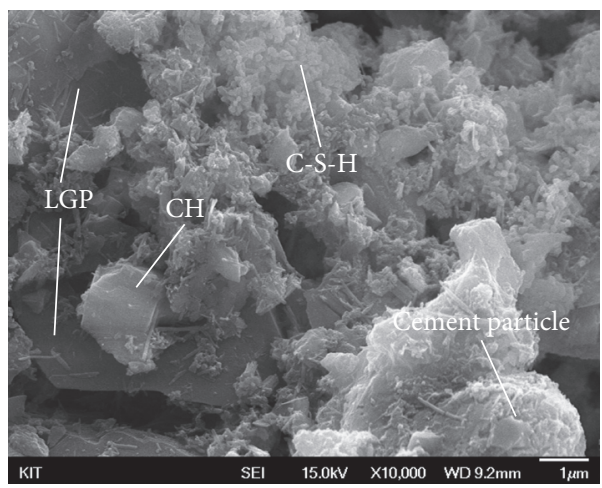

FIGURE 10: SEM image of composition paste which contained LGP12 $10 \%$ (3 days).

ages of concrete hydration, on 3 and 28 days, by using SEM images. An EDX analysis was performed to identify the atoms and their weight ratios from the SEM images. The SEM image in Figure 9 shows the microstructure of OPC on 3 days. The OPC was hydrated in a typical manner to produce C$\mathrm{S}-\mathrm{H}$ and $\mathrm{Ca}(\mathrm{OH})_{2}$ hydrates, but the darker regions of the image indicate that a considerable amount of water or air was included in the pores.

Figure 10 is a SEM image of LGP12 10\%, and Figure 11 shows the EDX analysis results of LGP12 10\%. The LGP12 $10 \%$ specimen shown in Figures 10 and 11 had a cement paste structure where LGP having a material age of 3 days was substituted, as in the case of the specimen shown in Figure 9. Figure 10 verifies that the LGP particles stably existed between the C-S-H (gel) and C-H hydrates (crystals). LGP has a wave pattern on the cutting section due to the high hardness. The image of the LGP particles on 3 days showed that a significant amount of hydrates had already been generated but the LGP particles were not fully involved in the Pozzolanic reaction. This result showed that the LGP particles, unlike cement, did not immediately participate in the hydration reaction with water in early age. This indicates that a high LGP replacement ratio in concrete may have a negative effect on strength at early age. Figure 11 shows the results of the surface component investigation through EDX, indicating that it is rich in $\mathrm{Si}, \mathrm{O}$ 


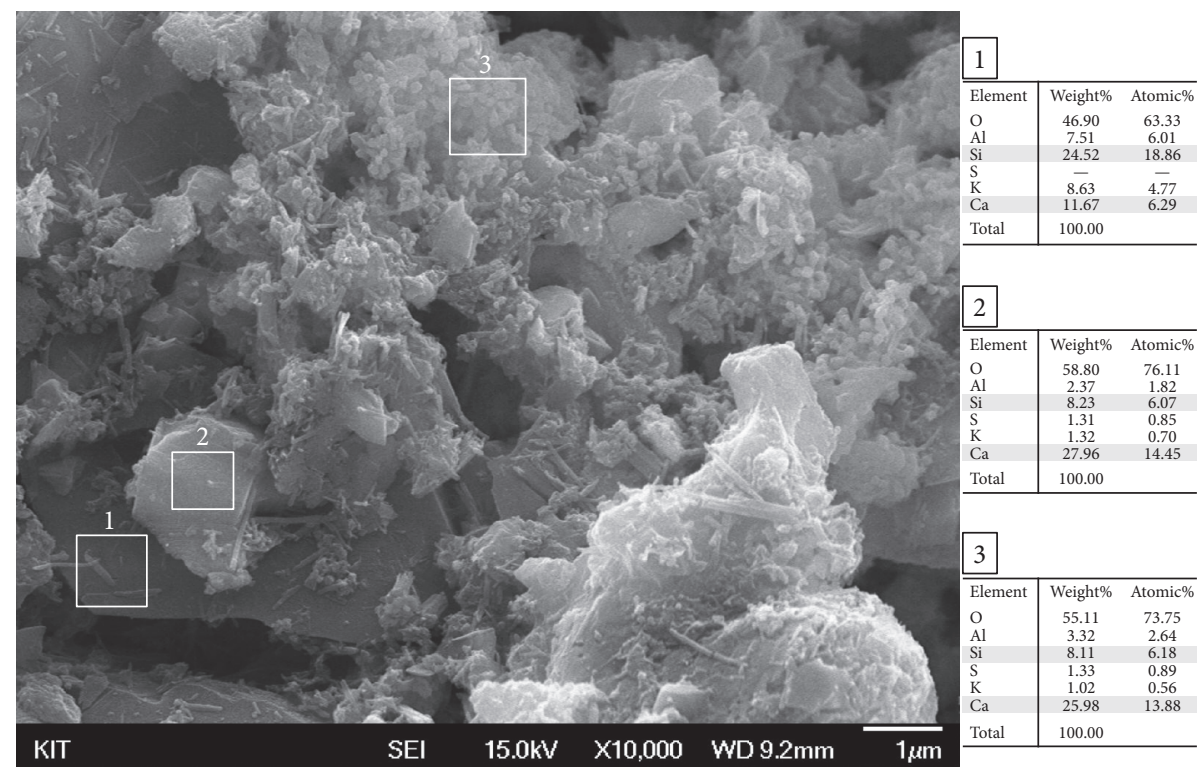

FIGURE 11: SEM view and chemical detected property by EDX of LGP12 10\% (3 days).

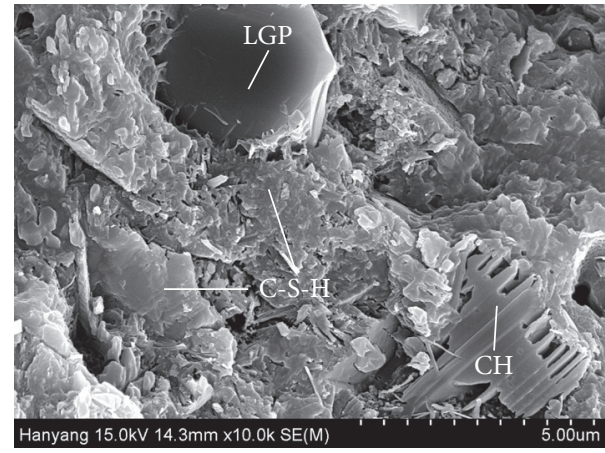

FIGURE 12: SEM image of composition paste which contained LGP12 $10 \%$ (28 days).

and has a material composition similar to that of LGP raw material.

Figures 12 and 13 show the microstructure of the LGP cement paste on 28 days. As shown in Figure 12, the structure included well-developed hydrates and was more compact than of OPC, such that independent LGP particles could not be identified. LGP particles were assimilated with cement paste and partially existed inside the hydrates. The dark regions containing pores were significantly reduced, and increase of C-S-H hydrates closely reflected the hydrate composition as a result of the Pozzolanic reaction. The binding of $\mathrm{C}-\mathrm{S}-\mathrm{H}$ hydrates to apparent LGP particles was found in the microstructure, indicating that the Pozzolanic reaction occurred more easily on crushed edge sections than on the relatively smooth and stable surfaces. The EDX analysis on 7 and 28 days showed that the $\mathrm{C} / \mathrm{S}$ ratio of the $\mathrm{C}-\mathrm{S}-\mathrm{H}$ hydrates was changed with time. The increased calcium content on 28 days might have affected the improvement of the strength of the concrete.
TABLE 6: Comparison of reduction average pore diameter.

\begin{tabular}{lcc}
\hline & \multicolumn{2}{c}{ Average pore diameter $(\mathrm{nm})$} \\
& 7 days & 28 days \\
\hline OPC & 17.7926 & 14.4250 \\
LGP12 5\% & 16.3242 & 13.6883 \\
LGP12 10\% & 16.9954 & 13.7393 \\
LGP5 5\% & 18.3079 & 13.7930 \\
LGP5 10\% & 19.2284 & 13.2687 \\
\hline
\end{tabular}

3.7. MIP. The pore distribution in the cement matrix is generally dependent on the quantity of hydrates, because the pores are distributed by the hydrates contained in the cement matrix. The results shown in Figure 14 indicate that porosity of the high fineness LGP5 on 7 days was 18.31\% in LGP5 5\% and $19.23 \%$ in LGP5 10\%, which were higher than that of OPC. However, the entire LGP porosity was reduced, which was lower than 7 days by $2.6 \%$ to $6 \%$. The decrease of the porosity is closely related to the strength, consistent with the results described in Section 3.4. The Pozzolanic reaction is generally slower than the cement hydration reaction of OPC. Hence, concrete has been replaced with the Pozzolanic material showing high permeability in early age, but the permeability is decreased as the reactions progress. Since the capillary porosity is related to permeability, the addition of LGP may reduce permeability to contribute to improvement of the material durability.

The hydration reaction and the secondary Pozzolanic reaction reduced the capillary porosity in the entire pore size range, except the capillary pore (medium size) range, and decreased the maximum pore size. Table 6 shows the average pore size of LGP concrete depending on curing ages. The decrease of the pores was significant particularly in the pore size range from 50 to $110 \mathrm{~nm}$. Considering LGP particle 


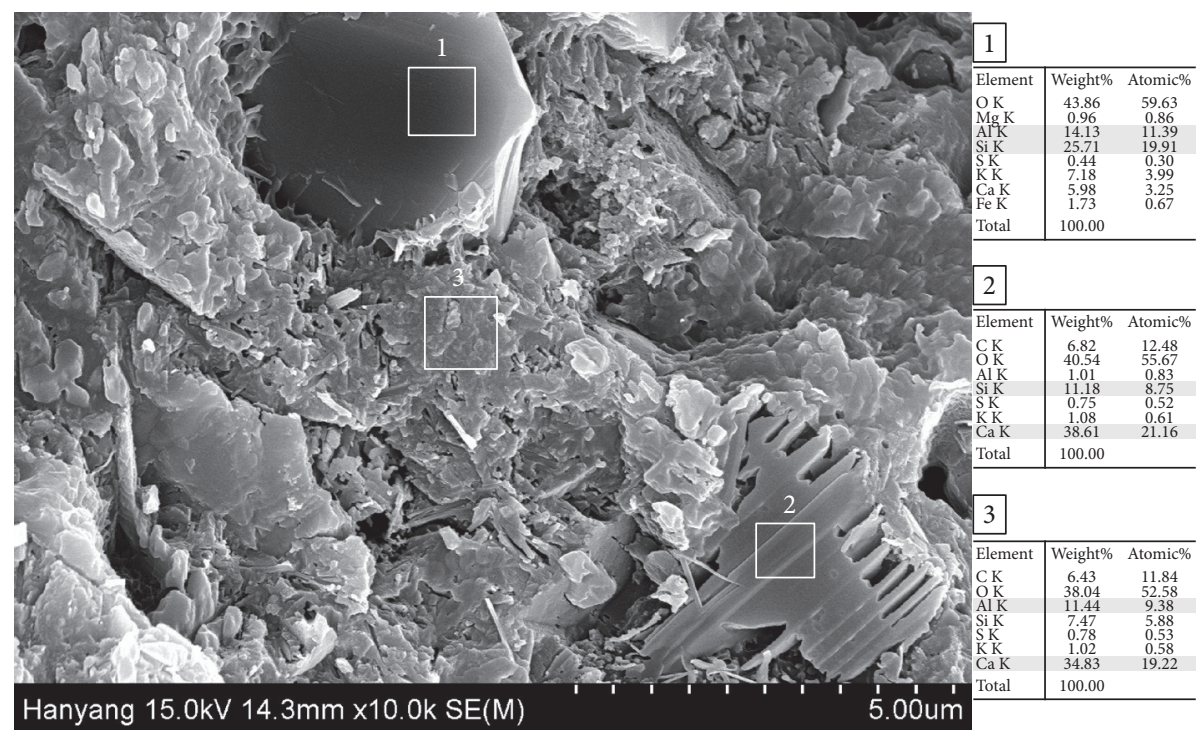

FIGURE 13: SEM view and chemical detected property by EDX of LGP12 10\% (28 days).

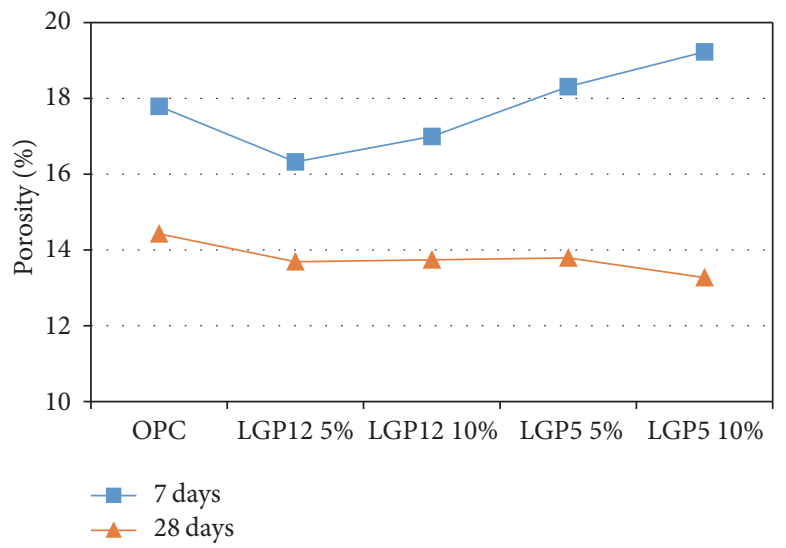

FIGURE 14: Porosity characteristics of concrete with LGP.

size distribution, the decrease of pores in this range may not be ascribed simply to the pore filling effect of LGP. Rather, as the cement paste was sufficiently hydrated, the produced hydrates developed a compact structure to block and divide the interconnected capillaries, producing pores that are interconnected with only gel pores. This might have considerably contributed to the increase of the strength [29]. In particular, the porosity in the capillary pore (medium size) range including gel pores of 4 to $50 \mathrm{~nm}$ was higher in the LGP specimen on 28 days than 7 days. The large pores decreased, but the capillary pores smaller than $50 \mathrm{~nm}$ increased when compared with the OPC. This indicates that the filling of LGP particles in the large-sized capillary pore range as well as the production of hydrates through the Pozzolanic reaction might have filled or divided the largesized capillary pores, converting the interconnected pores into closed pores [30]. As LGP replacement of cement was increased, the interconnected pores were converted into smaller pores regardless of the particle size. In addition, in the pore size range from 50 to $200 \mu \mathrm{m}$ (Interfacial Transition
Zone, ITZ), the porosity of LGP concrete was considerably decreased on 28 days. Figure 15 shows that the porosity decrease of OPC in this pore size range was not significant on 7 and 28 days. On the contrary, as shown in Figure 16, the porosity of all the LGP was significantly decreased in this pore size range. The particle size distribution of LGP5 shown in Figure 1 indicates that the specimen did not include particles of size around $100 \mu \mathrm{m}$. However, according to the results shown in Figure 16, the porosity of the LGP specimens in this pore size range decreased to a similar level, regardless of the particle size. This suggests that the hydrates produced during 28 days might have made the pores more compact and dense, thereby increasing the strength. The pore distribution and the pore size decrease in the ITZ were verified through a chloride ion permeability test conducted with concrete specimens produced by mixing Pozzolanic materials, such as SF, BS, and FA [31]. The most significant factors were a compact densification filling of microparticles and a modification of the hydration process [32]. This indicates that the mixing of concrete LGP materials may reduce the porosity of the 


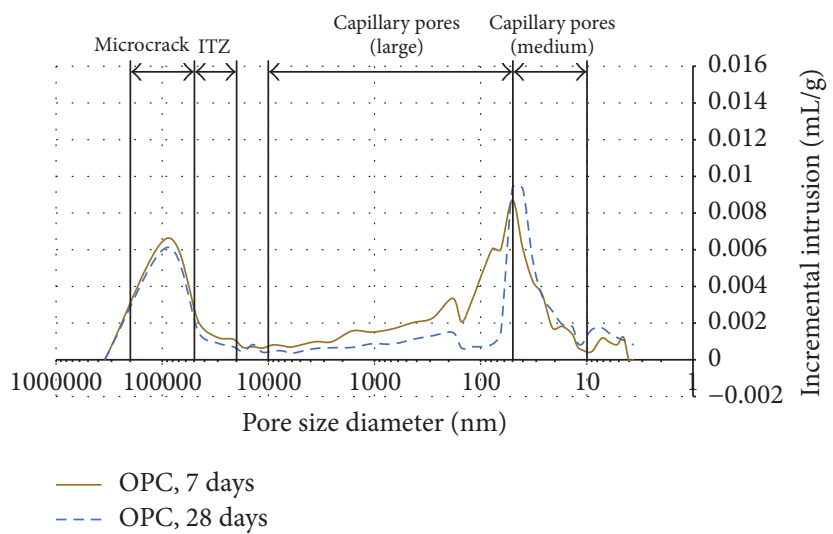

FIGURE 15: Relationship incremental intrusion and pore size diameter distribution with OPC.

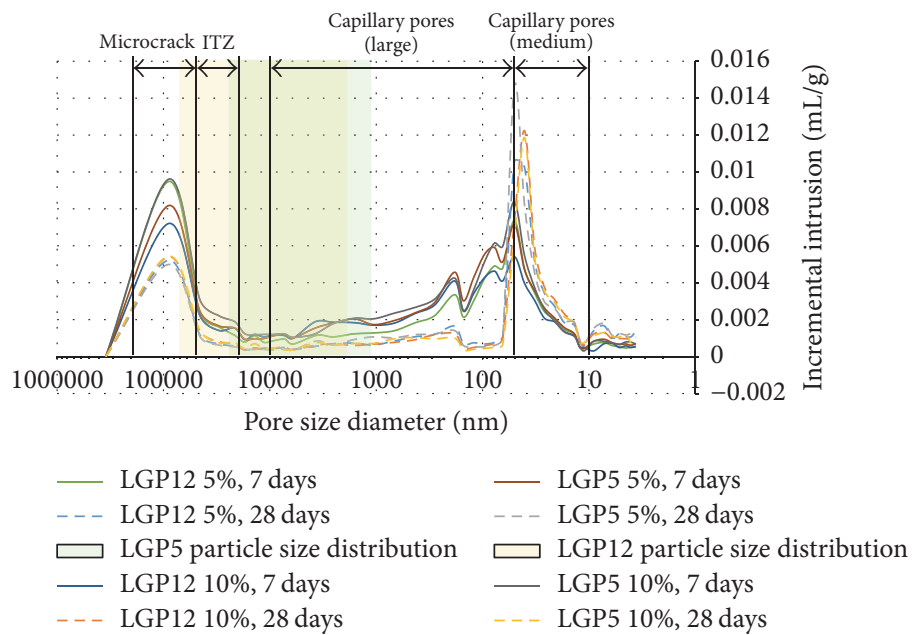

FIGURE 16: Relationship incremental intrusion and pore size diameter distribution with LGP according to replacement and age.

concrete system, increase the matrix density, and develop the strength.

\section{Conclusion}

In this study, LGP, which is one of the LPWG and made in Republic of Korea, replaced the cement depending on the ratio. LGP is much smaller than cement. It demonstrated the good performance and utilization possibilities of replacement. Results from the experiment are as follows.

(1) In the case of LGP concrete, it showed lower air content than OPC. In particular, when the LGP12 replaced $10 \%$, it showed the lowest amount of air content. LGP5 concrete showed similar air content with OPC. Considering the replacement dosage of cement and high fineness of LGP, the use of admixture (SP) is considered appropriate for improvement of workability, freeze-thaw resistance, and durability.

(2) LGP12 has 9\% higher slump than OPC in 5\% replacement, due to the smooth surface and low absorption of the LGP. However, the slump decreases while the replacement is increasing. In the case of LGP5, slump was $16 \%$ lower than OPC in 5\% replacement. The slump tends to drop with an increasing LGP replacement and high fineness.

(3) Compressive strength of LGP is higher than OPC in 28 days. The highest compressive strength showed in $10 \%$ replacement, which is the highest in LGP5. The tendency of strength development showed lower strength than OPC in the replacement of over $15 \%$ until 3 days. But after 7 days, entire compressive strength of LGP is higher than OPC. After 14 days, the compressive strength activity was increased due to the pozzolanic reaction.

(4) Entire splitting tensile strength is higher than OPC in 28 days. The maximum development was $83 \%$ in LGP5 5\%, indicating that increasing LGP replacement would result in a decrease in splitting tensile strength. In case of LGP5 replacement, it showed the lowest level of splitting tensile strength development (19\% increased). Relationship of splitting tensile strength by compressive strength ratio indicated $4.5 \sim 7.4 \%$ level. 
(5) SEM results indicate that the dense hydrate was produced at the interface between the LGP and the cement paste, which can verify some of LGP with C$\mathrm{S}-\mathrm{H}$ gel. The compressive strength of LGP concrete may have a deleterious effect with increased LGP replacement in early age, because low cement content may deteriorate the hydration reaction.

(6) The porosity of LGP concrete is decreased, which is expected to have a positive effect on improving durability and permeability. Therefore, the result of hydration and pozzolanic reaction showed a tendency to transfer pores to a relatively smaller pore distribution pattern. Furthermore, Capillary porosity of $50 \sim 110 \mathrm{~nm}$ and ITZ of 50 200 $\mu \mathrm{m}$ indicated porosity reduction which means that an increase in the density and a decrease in the porosity with LGP.

\section{Competing Interests}

The authors declare that they have no competing interests.

\section{Acknowledgments}

This research was supported by a grant from R\&D Program funded by Ministry of Land, Infrastructure and Transport of Korean government (16RDRP-B076268-03).

\section{References}

[1] M. Schneider, M. Romer, M. Tschudin, and H. Bolio, "Sustainable cement production-present and future," Cement and Concrete Research, vol. 41, no. 7, pp. 642-650, 2011.

[2] M. M. Hossain, M. R. Karim, M. Hasan, M. K. Hossain, and M. F. M. Zain, "Durability of mortar and concrete made up of pozzolans as a partial replacement of cement: a review," Construction and Building Materials, vol. 116, pp. 128-140, 2016.

[3] M. Batayneh, I. Marie, and I. Asi, "Use of selected waste materials in concrete mixes," Waste Management, vol. 27, no. 12, pp. 1870-1876, 2007.

[4] H.-Y. Wang, "The effect of the proportion of thin film transistor-liquid crystal display (TFT-LCD) optical waste glass as a partial substitute for cement in cement mortar," Construction and Building Materials, vol. 25, no. 2, pp. 791-797, 2011.

[5] D. Y. Shin, L. S. Kang, J. L. Park, C. G. Lee, J. H. Yoon, and H. S. Hong, "Current research trend on recycling of waste flat panel display panel glass," Journal of the Korean Institute of Resources Recycling, vol. 24, no. 1, pp. 58-65, 2015.

[6] S. Lee, L. Kang, C. G. Lee, M. H. Hong, S. Cho, and H. S. Hong, "Disassembly and compositional analysis of waste LCD displays," Journal of the Korean Institute of Resources Recycling, vol. 22, no. 2, pp. 29-36, 2013.

[7] K. Kim, K. Kim, and J. Hwang, "LCD waste glass as a substitute for feldspar in the porcelain sanitary ware production," Ceramics International, vol. 41, no. 5, pp. 7097-7102, 2015.

[8] C. Shi, Y. Wu, Y. Shao, and C. Riefler, "Alkali-aggregate reaction of concrete containing ground glass powder," in Proceedings of the 12th International Conference on AAR in Concrete, pp. 789795, 2004.

[9] H. Woods, Durability of Concrete, ACI Monograph 4, American Concrete Institute, Detroit, Mich, USA, 1968.
[10] K. Zheng, "Pozzolanic reaction of glass powder and its role in controlling alkali-silica reaction," Cement and Concrete Composites, vol. 67, pp. 30-38, 2016.

[11] K. Afshinnia and P. R. Rangaraju, "Influence of fineness of ground recycled glass on mitigation of Alkali-silica reaction in mortars," Construction and Building Materials, vol. 81, pp. 257267, 2015.

[12] C. S. Lam, C. S. Poon, and D. Chan, "Enhancing the performance of pre-cast concrete blocks by incorporating waste glass-ASR consideration," Cement and Concrete Composites, vol. 29, no. 8, pp. 616-625, 2007.

[13] A. Saccani and M. C. Bignozzi, "ASR expansion behavior of recycled glass fine aggregates in concrete," Cement and Concrete Research, vol. 40, no. 4, pp. 531-536, 2010.

[14] M. E.-S. I. Saraya, "Study physico-chemical properties of blended cements containing fixed amount of silica fume, blast furnace slag, basalt and limestone, a comparative study," Construction and Building Materials, vol. 72, pp. 104-112, 2014.

[15] C. Shi and K. Zheng, "A review on the use of waste glasses in the production of cement and concrete," Resources, Conservation and Recycling, vol. 52, no. 2, pp. 234-247, 2007.

[16] H.-Y. Wang, "A study of the effects of LCD glass sand on the properties of concrete," Waste Management, vol. 29, no. 1, pp. 335-341, 2009.

[17] W. Her-Yung, "A study of the engineering properties of waste LCD glass applied to controlled low strength materials concrete," Construction and Building Materials, vol. 23, no. 6, pp. 2127-2131, 2009.

[18] H.-Y. Wang and W.-L. Huang, "Durability of self-consolidating concrete using waste LCD glass," Construction and Building Materials, vol. 24, no. 6, pp. 1008-1013, 2010.

[19] H.-Y. Wang, H.-H. Zeng, and J.-Y. Wu, "A study on the macro and micro properties of concrete with LCD glass," Construction and Building Materials, vol. 50, pp. 664-670, 2014.

[20] K. L. Lin, W.-J. Huang, J. L. Shie, T. C. Lee, K. S. Wang, and C. H. Lee, "The utilization of thin film transistor liquid crystal display waste glass as a pozzolanic material," Journal of Hazardous Materials, vol. 163, no. 2-3, pp. 916-921, 2009.

[21] M. Á. Sanjuán, C. Argiz, J. C. Gálvez, and A. Moragues, "Effect of silica fume fineness on the improvement of Portland cement strength performance," Construction and Building Materials, vol. 96, pp. 55-64, 2015.

[22] N. A. Soliman and A. Tagnit-Hamou, "Development of ultra-high-performance concrete using glass powder-towards ecofriendly concrete," Construction and Building Materials, vol. 125, pp. 600-612, 2016.

[23] C. Shi, Y. Wu, C. Riefler, and H. Wang, "Characteristics and pozzolanic reactivity of glass powders," Cement and Concrete Research, vol. 35, no. 5, pp. 987-993, 2005.

[24] S. Mindess, F. Young, and D. Darwin, Concrete, Prentice-Hall, Upper Saddle River, NJ, USA, 2003.

[25] L. M. Federico and S. E. Chidiac, "Waste glass as a supplementary cementitious material in concrete-critical review of treatment methods," Cement and Concrete Composites, vol. 31, no. 8, pp. 606-610, 2009.

[26] Y. Shao, T. Lefort, S. Moras, and D. Rodriguez, "Studies on concrete containing ground waste glass," Cement and Concrete Research, vol. 30, no. 1, pp. 91-100, 2000.

[27] C. Meyer, S. Baxter, and W. Jin, "Potential of waste glass for concrete masonry blocks," in Proceedings of the 4th Materials Engineering Conference, pp. 666-673, Washington, DC, USA, 1996. 
[28] J. E. Mcdonald, "Properties of silica fume concrete," Tech. Rep. REMR-CS-32, REMR Research Program, U.S. Army Engineer Waterways Experiment Station, Vicksburg, Miss, USA, 1991.

[29] R. D. Hooton, "Permeability and pore structure of cement pastes containing fly-ash, slag, and silica fume," Blended Cements ASTM STP-897, ASTM, West, 1986.

[30] P. Chindaprasirt, C. Jaturapitakkul, and T. Sinsiri, "Effect of fly ash fineness on compressive strength and pore size of blended cement paste," Cement and Concrete Composites, vol. 27, no. 4, pp. 425-428, 2005.

[31] P. Plante and A. Bilodeau, "Rapid chloride ion permeability test: data on concretes incorporating supplementary cementing materials," in Fly Ash, Silica Fume, Slag, and Natural Pozzolans in Concrete: Proceedings, Third International Conference, Trondheim, Norway, 1989, American Concrete Institute, 1989.

[32] J. P. Ollivier, J. C. Maso, and B. Bourdette, "Interfacial transition zone in concrete," Advanced Cement Based Materials, vol. 2, no. 1, pp. 30-38, 1995. 

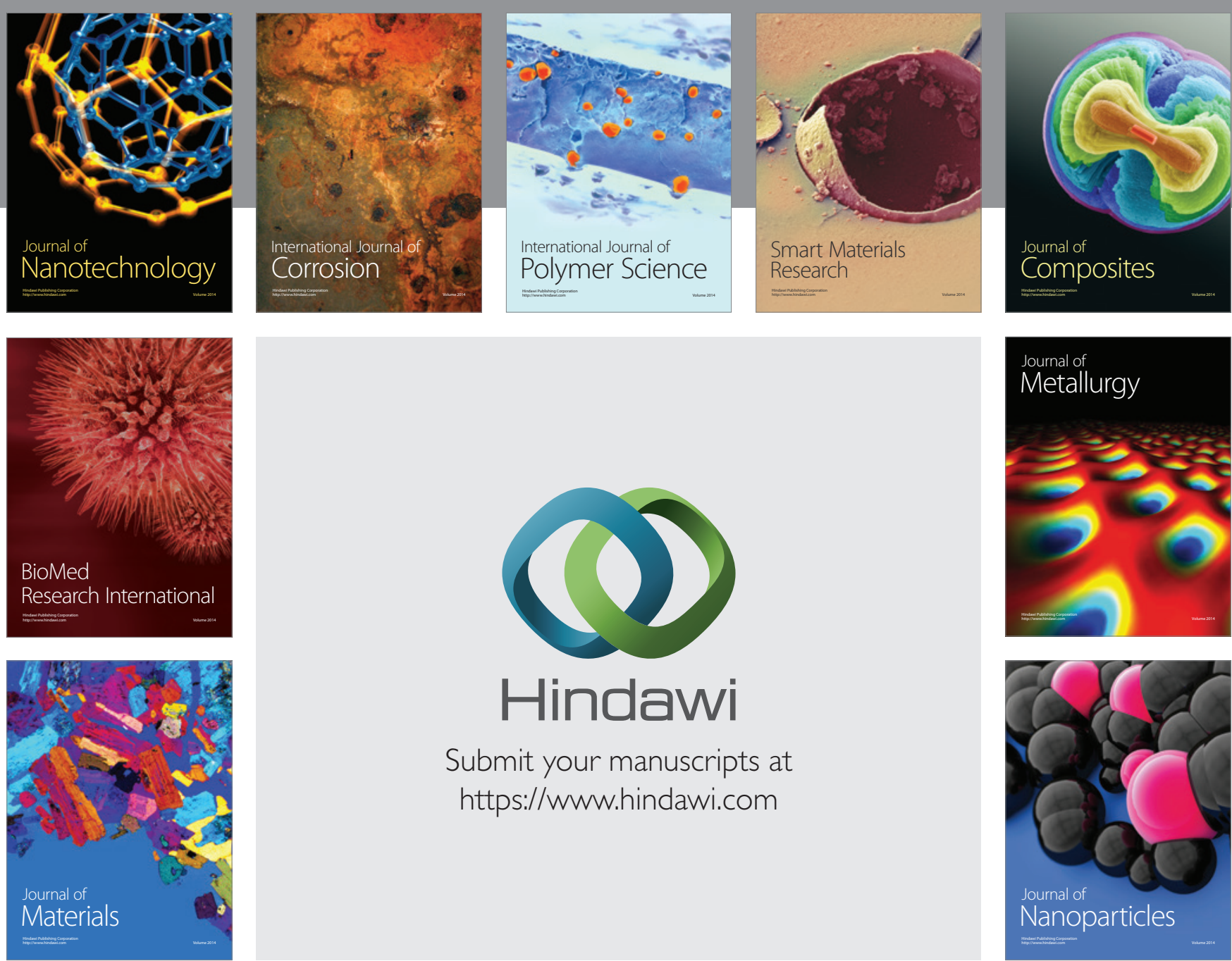

\section{Hindawi}

Submit your manuscripts at

https://www.hindawi.com

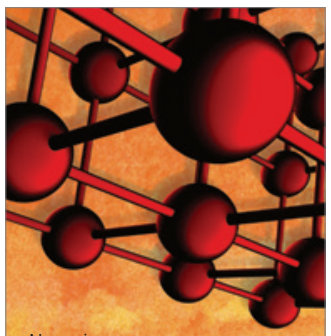

Materials Science and Engineering
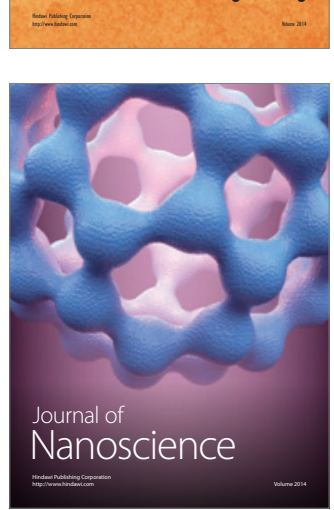
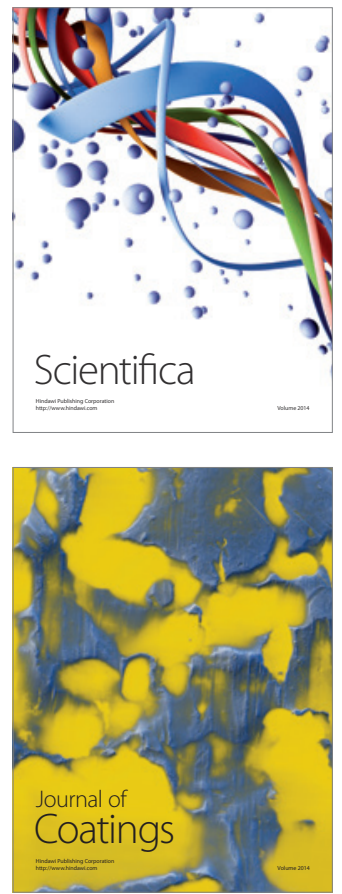
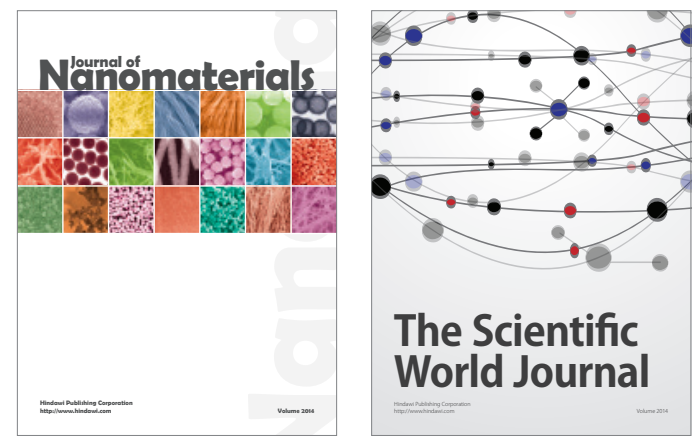

The Scientific World Journal
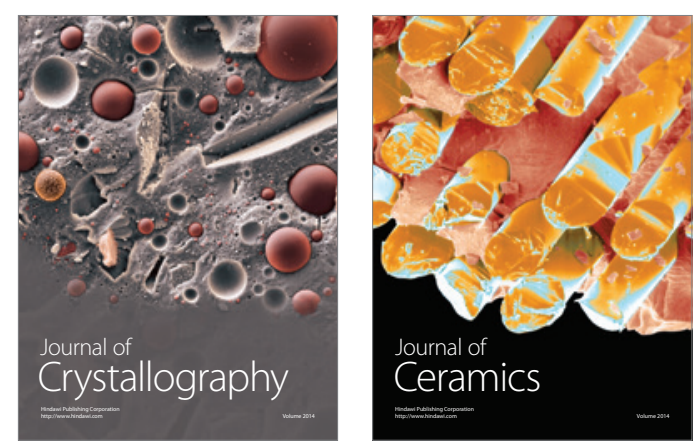
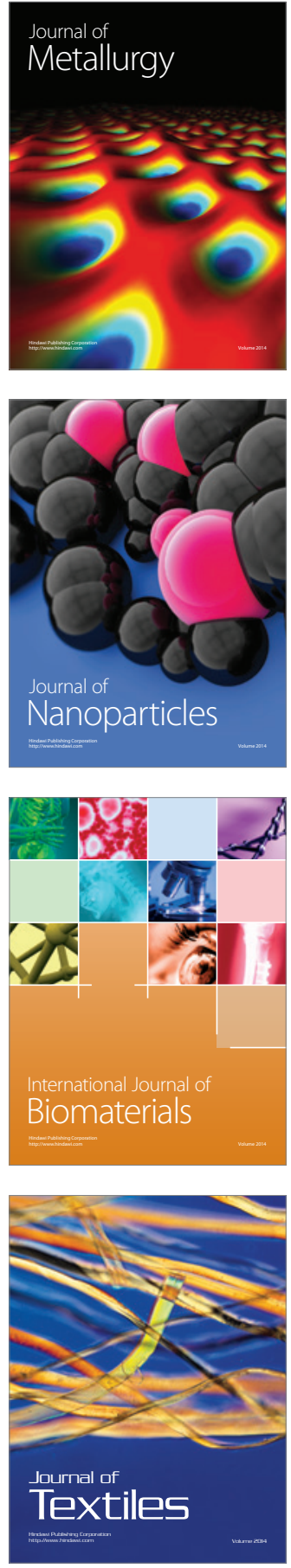